Note

\title{
Effect of Dietary Soybean Protein Level on the Plasma Homocysteine Concentration in Rats
}

\author{
Hiroshi Okawa, Tatsuya Morita, and Kimio Sugiyama ${ }^{\dagger}$ \\ Department of Applied Biological Chemistry, Faculty of Agriculture, Shizuoka University, \\ 836 Ohya, Shizuoka 422-8529, Japan
}

Received December 6, 2007; Accepted February 11, 2008; Online Publication, June 7, 2008

[doi:10.1271/bbb.70797]

There was an inverse correlation between the plasma homocysteine concentration and dietary protein level or protein intake when a soybean protein isolate (SPI) was used as a protein source for rats. The hepatic cystathionine $\beta$-synthase activity increased in response to the dietary SPI level. The results suggest that a high-protein diet might be an effective means to lower the plasma homocysteine concentration, probably through enhancement of the homocysteine-metabolizing activity.

Key words: homocysteine; dietary protein level; soybean protein isolate; methionine; rat

Although homocysteine is the usual metabolite of methionine, an elevated plasma homocysteine concentration is known to be an independent risk factor for cardiovascular disease. ${ }^{1-3)}$ An increase of $5 \mu \mathrm{M}$ in this amino acid concentration is associated with an increase in coronary heart disease risk by $60-80 \% .^{2)}$ It has been reported that the plasma homocysteine concentration was influenced by various factors, including dietary and nutritional conditions. ${ }^{1-4)}$ It would be interesting to identify the relationship between the protein intake and plasma homocysteine concentration, since methionine is the sole precursor of homocysteine and the intake of methionine is usually associated with the protein intake. Several studies have been reported concerning the effect of dietary protein intake on the plasma homocysteine concentration in humans ${ }^{5-10)}$ and rats. ${ }^{11-13)}$ However, the results of previous studies are not consistent. For instance, the plasma homocysteine concentration was significantly higher in rats fed on a high $(60 \%)$ casein diet than in rats fed on a standard $(20 \%)$ casein diet, ${ }^{12)}$ whereas we have demonstrated that the plasma homocysteine concentration was significantly higher in rats fed on a low $(10 \%)$ casein diet than in rats fed on a relatively high $(30 \%)$ casein diet. $\left.{ }^{13}\right)$ The latter observation that a higher protein intake decreased the plasma homocysteine concentration despite the methionine intake being higher appears to be an interesting paradox.
However, the effects of the dietary protein level and/or dietary protein source on the plasma homocysteine concentration have not yet been fully elucidated.

We investigated in this study the effect of dietary protein level on the plasma homocysteine concentration in rats by using soybean protein, a representative plant protein, at dietary levels of $15 \%, 25 \%$ and $50 \%$ to test the foregoing paradox. The effects of supplementing the low (15\%) soybean protein diet with small amounts of sulfur amino acids were also investigated to examine the relationship between the plasma homocysteine concentration and sulfur amino acid deficiency or growth retardation.

Male six-week-old rats (120-140 g) of the Wistar strain were obtained from Japan SLC (Hamamatsu, Japan). In experiment 1 , the rats were fed on diets containing graded levels of a soybean protein isolate (SPI; Fuji Oil, Izumisano, Japan). The composition of the diets containing SPI at levels of $15 \%$ (15S), $25 \%$ (25S) and 50\% (50S) was as follows (g/100 g): SPI, 15, 25 or 50 ; corn starch, $53.25,43.25$ or 18.25 ; sucrose, 20 ; corn oil, 5; AIN-93G mineral mixture, 3.5; AIN-93G vitamin mixture, 1 ; choline bitartrate, 0.25 ; cellulose, 2 . In experiment 2 , L-methionine $(0.30 \%)$ or an equimolar amount of L-cysteine $(0.24 \%)$ was added to the $15 \mathrm{~S}$ diet at the expense of starch. After rats had been given free access to water and the experimental diets for $14 \mathrm{~d}$, they were killed by decapitation between 10.00 and $10.30 \mathrm{~h}$ to obtain the blood and liver. The experimental plan was approved by the Laboratory Animal Care Committee of the Faculty of Agriculture at Shizuoka University.

After collecting the blood, the whole liver was quickly removed, rinsed in ice-cold saline, blotted on filter paper, cut into two portions, weighed, quickly frozen in liquid nitrogen and stored at $-80^{\circ} \mathrm{C}$ until needed for analyses. One portion of the liver was homogenized in 4 volumes (vol/wt) of ice-cold $5 \%$ perchloric acid and then centrifuged at $10,000 \times g$ for $10 \mathrm{~min}$ at $4{ }^{\circ} \mathrm{C}$. The supernatant of the deproteinized liver homogenate was subjected to assays of methionine

$\dagger$ To whom correspondence should be addressed. Fax: +81-54-238-4877; E-mail: acksugi@agr.shizuoka.ac.jp

Abbreviations: CBS, cystathionine $\beta$-synthase; SAH, $S$-adenosylhomocysteine; SAM, $S$-adenosylmethionine; SPI, soybean protein isolate 
Table 1. Effects of Dietary Soybean Protein Level on the Plasma Homocysteine Concentration and Other Variables in Rats (experiment 1$)^{1}$

\begin{tabular}{lccc}
\hline \hline & \multicolumn{3}{c}{ Diet } \\
\cline { 2 - 4 } & $15 \mathrm{~S}$ & $25 \mathrm{~S}$ & $50 \mathrm{~S}$ \\
\hline Body wt. gain $(\mathrm{g} / 14 \mathrm{~d})$ & $50 \pm 1^{\mathrm{c}}$ & $60 \pm 2^{\mathrm{b}}$ & $67 \pm 2^{\mathrm{a}}$ \\
Food intake $(\mathrm{g} / 14 \mathrm{~d})$ & $228 \pm 5^{\mathrm{a}}$ & $202 \pm 3^{\mathrm{b}}$ & $193 \pm 4^{\mathrm{b}}$ \\
Protein intake $(\mathrm{g} / 14 \mathrm{~d})$ & $29.4 \pm 0.6^{\mathrm{c}}$ & $43.4 \pm 0.6^{\mathrm{b}}$ & $83.0 \pm 1.7^{\mathrm{a}}$ \\
Methionine intake $(\mathrm{g} / 14 \mathrm{~d})$ & $0.39 \pm 0.01^{\mathrm{c}}$ & $0.58 \pm 0.01^{\mathrm{b}}$ & $1.10 \pm 0.02^{\mathrm{a}}$ \\
Liver wt. (\% of body wt.) & $3.89 \pm 0.04^{\mathrm{b}}$ & $3.91 \pm 0.04^{\mathrm{b}}$ & $4.57 \pm 0.02^{\mathrm{a}}$ \\
Plasma: & & & \\
$\quad$ Homocysteine ( $\mu$ mol/l) & $14.9 \pm 0.4^{\mathrm{a}}$ & $12.9 \pm 0.2^{\mathrm{b}}$ & $9.7 \pm 0.3^{\mathrm{c}}$ \\
$\quad$ Cysteine $(\mu \mathrm{mol} / \mathrm{l})$ & $150 \pm 7$ & $145 \pm 4$ & $152 \pm 5$ \\
Liver: & & & \\
$\quad$ SAM (nmol/g) & $62 \pm 1^{\mathrm{b}}$ & $66 \pm 4^{\mathrm{b}}$ & $79 \pm 4^{\mathrm{a}}$ \\
SAH (nmol/g) & $12.6 \pm 0.4^{\mathrm{b}}$ & $15.9 \pm 0.5^{\mathrm{a}}$ & $17.2 \pm 0.7^{\mathrm{a}}$ \\
SAM/SAH ratio & $4.7 \pm 0.3$ & $4.6 \pm 0.4$ & $4.3 \pm 0.4$ \\
Homocysteine (nmol/g) & $2.3 \pm 0.4$ & $1.5 \pm 0.4$ & $2.6 \pm 0.5$ \\
CBS activity & $4.7 \pm 0.2^{\mathrm{c}}$ & $6.1 \pm 0.1^{\mathrm{b}}$ & $7.2 \pm 0.3^{\mathrm{a}}$ \\
\hline
\end{tabular}

${ }^{1}$ Each value is the mean \pm SEM, $n=7$. Means without a common superscript letter differ at $p<0.05$. 15S, 25S and 50S represent the diets containing the soybean protein isolate at levels of $15 \%, 25 \%$ and $50 \%$, respectively. CBS, cystathionine $\beta$-synthase; SAH, $S$-adenosylhomocysteine; SAM, $S$-adenosylmethionine

${ }^{2}$ Enzyme activity is expressed as $\mathrm{nmol} / \mathrm{min} / \mathrm{mg}$ of protein.

metabolites. The other portion of the liver was homogenized in 4 volumes (vol/wt) of a $10 \mathrm{~mm}$ sodium phosphate buffer ( $\mathrm{pH} 7.4$ ) containing $150 \mathrm{mM} \mathrm{KCl}$, and the resulting homogenate was centrifuged at 14,000 $\times g$ for $10 \mathrm{~min}$ at $4{ }^{\circ} \mathrm{C}$. The supernatant was subjected to an enzyme assay. The concentrations of total homocysteine and cysteine in the plasma were measured by HPLC according to Durand et al. ${ }^{14)}$ The concentrations of S-adenosylmethionine (SAM) and S-adenosylhomocysteine $(\mathrm{SAH})$ in the liver were measured by HPLC essentially according to Cook et al. ${ }^{15)}$ The activity of cystathionine $\beta$-synthase (E.C. 4.2.1.22; CBS) in the liver was measured according to Mudd et al., ${ }^{16)}$ but HPLC was used for the assay of the reaction product cystathionine according to Einarsson et al. ${ }^{17)}$ Data were analyzed by a one-way analysis of variance, and the differences among experimental groups were analyzed by a Tukey test when the $F$ value was significant.

The results of experiment 1 are summarized in Table 1 . The body weight gain significantly increased with the increase in dietary SPI level, whereas the food intake was significantly lower in the rats fed on the $25 \mathrm{~S}$ and $50 \mathrm{~S}$ diets than in the rats fed on the $15 \mathrm{~S}$ diet. The relative liver weight was significantly higher in the rats fed on the 50S diet than in rats fed on the other diets. The plasma homocysteine concentrations in the rats fed on the $15 \mathrm{~S}, 25 \mathrm{~S}$ and $50 \mathrm{~S}$ diets were significantly higher in that order. In contrast, the plasma cysteine concentration was unaffected by the dietary SPI level. The hepatic SAM and SAH concentrations increased or tended to increase with increasing dietary SPI level, whereas the hepatic homocysteine concentration was unaffected by the dietary SPI level. The hepatic CBS activity significantly increased in response to the dietary
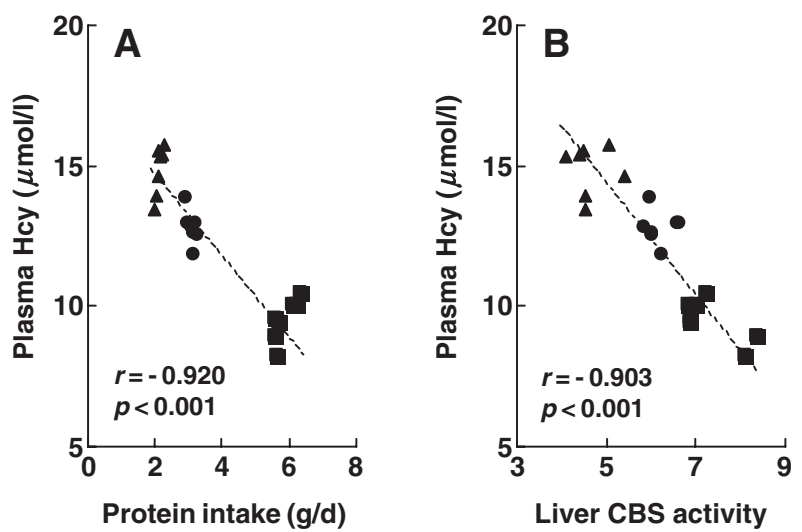

Fig. 1. Correlation between the Plasma Homocysteine Concentration and Mean Daily Protein Intake (A) or Hepatic Cystathionine $\beta$ Synthase Activity (B) in Rats Fed on Diets Containing a 15\%, $25 \%$ and $50 \%$ Soybean Protein Isolate.

The filled triangle, circle and square denote the values for individual rats fed on the $15 \%, 25 \%$ and $50 \%$ soybean protein diets, respectively. The enzyme activity is expressed as nmol/ $\mathrm{min} / \mathrm{mg}$ of protein. CBS, cystathionine $\beta$-synthase; Hcy, homocysteine.

Table 2. Effects of Supplementing a Low Soybean Protein Diet with $0.30 \%$ L-Methionine or $0.24 \%$ L-Cysteine on the Plasma Homocysteine and Cysteine Concentrations in Rats (experiment 2$)^{1}$

\begin{tabular}{lccc}
\hline \hline & \multicolumn{3}{c}{ Diet } \\
\cline { 2 - 4 } & $15 \mathrm{~S}$ & $15 \mathrm{~S}+$ Met & $15 \mathrm{~S}+\mathrm{Cys}$ \\
\hline Body wt. gain $(\mathrm{g} / 14 \mathrm{~d})$ & $48 \pm 3^{\mathrm{b}}$ & $65 \pm 4^{\mathrm{a}}$ & $50 \pm 3^{\mathrm{b}}$ \\
Food intake $(\mathrm{g} / 14 \mathrm{~d})$ & $226 \pm 5^{\mathrm{a}}$ & $203 \pm 6^{\mathrm{b}}$ & $195 \pm 5^{\mathrm{b}}$ \\
Liver wt $(\%$ of body wt.) & $3.84 \pm 0.05^{\mathrm{b}}$ & $4.10 \pm 0.05^{\mathrm{a}}$ & $4.19 \pm 0.07^{\mathrm{a}}$ \\
Plasma: & & & \\
$\quad$ Homocysteine $(\mu \mathrm{mol} / 1)$ & $15.2 \pm 0.5^{\mathrm{b}}$ & $18.1 \pm 0.8^{\mathrm{a}}$ & $7.2 \pm 0.6^{\mathrm{c}}$ \\
$\quad$ Cysteine $(\mu \mathrm{mol} / \mathrm{l})$ & $155 \pm 7^{\mathrm{b}}$ & $167 \pm 4^{\mathrm{b}}$ & $194 \pm 9^{\mathrm{a}}$ \\
\hline
\end{tabular}

${ }^{1}$ Each value is the mean $\pm \mathrm{SEM}, n=6$. Values without a common superscript letter differ at $p<0.05$. $15 \mathrm{~S}$ represents the diet containing the soybean protein isolate at a $15 \%$ level.

SPI level, and there was a significant inverse correlation between the plasma homocysteine concentration and dietary SPI level $(r=-0.947, p<0.001, n=21)$ or mean daily protein intake (Fig. 1A). A significant inverse correlation was also seen between the plasma homocysteine concentration and CBS activity (Fig. 1B). The results of experiment 2 are summarized in Table 2. Dietary supplementation of the $15 \mathrm{~S}$ diet with $0.30 \%$ methionine significantly increased the body weight gain, while supplementation with $0.24 \%$ cysteine did not affect the body weight gain. The food intake was significantly lower in the rats fed on diets supplemented with methionine or cysteine than in the rats fed on the $15 \mathrm{~S}$ diet. Methionine or cysteine supplementation significantly increased the relative liver weight. The plasma homocysteine concentration was significantly increased by methionine supplementation and, conversely, significantly decreased by cysteine supplementation. The plasma cysteine concentration was significantly increas- 
ed by cysteine supplementation, but not by methionine supplementation.

The results of the present study clearly demonstrate that the plasma homocysteine concentration was inversely correlated with the dietary SPI level or protein intake. The effect of dietary protein level on the plasma homocysteine concentration observed in the present study can be resolved in two ways: the hyperhomocysteinemic effect of the low SPI diet and the hypohomocysteinemic effect of the high SPI diet. The former effect confirms our previous finding that the plasma homocysteine concentration was significantly higher in rats fed on a $10 \%$ casein diet than in rats fed on a $30 \%$ casein diet. ${ }^{13)}$ These results suggest that a low-protein diet might bring about a higher plasma homocysteine concentration irrespective of the protein source. In contrast, the latter effect appears to be in conflict with the results of a study by Stead et al. ${ }^{12)}$ showing that the plasma homocysteine concentration was significantly higher in rats fed on a $60 \%$ casein diet than in rats fed on a $20 \%$ casein diet. This discrepancy may be due to a difference in the dietary protein level, rat strain, or other dietary conditions. On the other hand, our results appear to be consistent with the results of some observational human studies. For instance, Stolzenberg-Solomon et $a l .{ }^{6)}$ have reported that there was an inverse doseresponse relationship between the dietary protein intake and the plasma homocysteine concentration in older human populations in the USA. Furthermore, Nagata et $a l .{ }^{18)}$ have reported that the soy product intake was inversely associated with the serum homocysteine level in premenopausal Japanese women; there was a significant inverse correlation between the serum homocysteine concentration and soybean protein intake as well as with the intake of isoflavone, vitamin B-6 and folate.

Although homocysteine can be metabolized by either the remethylation pathway or trans-sulfuration pathway, the main pathway for homocysteine metabolism in rats fed on a diet containing a relatively high level of methionine is thought to be the latter. ${ }^{19)}$ Indeed, the activity of hepatic CBS, which catalyzes the cystathionine formation, increased in response to the dietary level of protein ${ }^{19,20)}$ or methionine. ${ }^{21)}$ The results of the present study also clearly demonstrate that the hepatic CBS activity significantly increased in response to the dietary SPI level and that there was a significant inverse correlation between the plasma homocysteine concentration and hepatic CBS activity. These results suggest that the increased hepatic CBS activity caused by a highSPI diet might help to prevent hyperhomocysteinemia due to the higher methionine intake. Furthermore, an increased supply of serine, another substrate of CBS, and its precursor glycine might assist the effective metabolism of homocysteine in rats fed on a high-SPI diet. The activity of hepatic betaine-homocysteine $S$-methyltransferase, the enzyme which catalyzes betaine-dependent homocysteine remethylation, has been shown to increase in rats fed on a high-protein diet. ${ }^{19,22)}$
Therefore, it seems likely that, in addition to the increased cystathionine formation, increased homocysteine remethylation also contributes to the hypohomocysteinemic effect of a high SPI-diet.

Low-protein diets depress the growth of animals in many cases, as observed in the present study. The first limiting amino acid of the $15 \mathrm{~S}$ diet is methionine. We therefore investigated the effect of supplementing the $15 \mathrm{~S}$ diet with a small amount of methionine or cysteine on the plasma homocysteine concentration to clarify whether a sulfur amino acid deficiency in the diet or the resulting growth retardation would be associated with the higher plasma homocysteine concentration in rats fed on the $15 \mathrm{~S}$ diet. The results show that methionine supplementation significantly improved the body weight gain of the rats and slightly increased the plasma homocysteine concentration, suggesting that neither the methionine deficiency nor growth retardation was associated with the higher plasma homocysteine concentration. In contrast, dietary supplementation with cysteine significantly decreased the plasma homocysteine concentration without improving animal growth. The hypohomocysteinemic effect of cysteine observed in the present study is consistent with the results of a study by Verhoef et al. ${ }^{10)}$ showing that a transient increase in the plasma homocysteine concentration due to a single ingestion of a low-protein meal supplemented with methionine was significantly suppressed by concurrent supplementation with cystine. Therefore, the possibility that the higher plasma homocysteine concentration in rats fed on the $15 \mathrm{~S}$ diet may have been partly due to the low cyst(e)ine intake cannot be excluded. However, further studies are needed to confirm this possibility.

\section{References}

1) Refsum, H., Ueland, P. M., Nygard, O., and Vollset, S. E., Homocysteine and cardiovascular disease. Аnпи. Rev. Med., 49, 31-62 (1998).

2) Selhub, J., Homocysteine metabolism. Annu. Rev. Nutr., 19, 217-246 (1999).

3) de Bree, A., Berschuren, W. M., Kromhout, D., Kluijtmans, L. A., and Blom, H. J., Homocysteine determinants and the evidence to what extent homocysteine determines the risk of coronary heart disease. Pharmacol. Rev., 54, 599-618 (2002).

4) Verhoef, P., and de Groot, L. C., Dietary determinants of plasma homocysteine concentrations. Semin. Vasc. Med., 5, 110-123 (2005).

5) Guttormsen, A. B., Schneede, J., Fiskerstrand, T., Ueland, P. M., and Refsum, H. M., Plasma concentrations of homocysteine and other aminothiol compounds are related to food intake in healthy human subjects. J. Nutr., 124, 1934-1941 (1994).

6) Stolzenberg-Solomon, R. Z., Miller III, E. R., Maguire, M. G., Selhub, J., and Appel, L. J., Association of dietary protein intake and coffee consumption with serum homocysteine concentrations in an older population. Am. J. Clin. Nutr., 69, 467-475 (1999). 
7) Jacques, P. F., Bostom, A. G., Wilson, P. W. F., Rich, S., Rosenberg, I. H., and Selhub, J., Determinants of plasma total homocysteine concentration in the Framingham Offspring cohort. Am. J. Clin. Nutr., 73, 613-621 (2001).

8) Haulrik, N., Toubro, S., Dyerberg, J., Stender, S., Skov, A. R., and Astrup, A., Effect of protein and methionine intakes on plasma homocysteine concentrations: a 6-mo randomized controlled trial in overweight subjects. Am. J. Clin. Nutr., 76, 1202-1206 (2002).

9) Noakes, M., Keogh, J. B., Foster, P. R., and Clifton, P. M., Effect of an energy-restricted, high-protein, lowfat diet relative to a conventional high-carbohydrate, low-fat diet on weight loss, body composition, nutritional status, and markers of cardiovascular health in obese women. Am. J. Clin. Nutr., 81, 1298-1306 (2005).

10) Verhoef, P., van Vliet, T., and Katan, M. B., A highprotein diet increases postprandial but not fasting plasma total homocysteine concentrations: a dietary controlled, crossover trial in healthy volunteers. Am. J. Clin. Nutr., 82, 552-558 (2005).

11) Smolin, L. A., and Benevenga, N. J., Factors affecting the accumulation of homocyst(e)ine in rats deficient in vitamin B-6. J. Nutr., 114, 103-111(1984).

12) Stead, L. M., Brosnan, M. E., and Brosnan, J. T., Characterization of homocysteine metabolism in the rat liver. Biochem. J., 350, 685-692 (2000).

13) Okawa, H., Morita, T., and Sugiyama, K., Increased plasma homocysteine concentration in rats from a low casein diet. Biosci. Biotechnol. Biochem., 70, 3050-3053 (2006).

14) Durand, P., Fortin, L. J., Luissier-Cacan, S., Davignon, J., and Blache, D., Hyperhomocysteinemia induced by folic acid deficiency and methionine load-application of a modified HPLC method. Clin. Chim. Acta, 252, 83-93 (1996).

15) Cook, R. J., Horne, D. W., and Wagner, C., Effect of dietary methyl group deficiency on one-carbon metabolism in rats. J. Nutr., 119, 612-617 (1988).

16) Mudd, S. H., Finkelstein, J. D., Irreverre, F., and Laster, L., Transsulfuration in mammals. Microassay and tissue distributions of three enzymes of the pathway. J. Biol. Chem., 240, 4382-4392 (1965).

17) Einarsson, S., Josefsson, B., and Lagerkvist, S., Detemination of amino acids with 9-fluorenylmethyl chloroformate and reversed-phase high-performance liquid chromatography. J. Chromatogr., 282, 609-618 (1983).

18) Nagata, C., Shimizu, H., Takami, R., Hayashi, M., Takeda, N., and Yasuda, K., Soy product intake is inversely associated with serum homocysteine level in premenopausal Japanese women. J. Nutr., 133, 797-800 (2003).

19) Finkelstein, J. D., and Martin, J. J., Methionine metabolism. Distribution of homocysteine between competing pathways. J. Biol. Chem., 259, 9508-9513 (1984).

20) Yamamoto, N., Tanaka, T., and Noguchi, T., The effect of a high-protein diet on cystathionine-synthase activity and its transcript levels in rat liver. J. Nutr. Sci. Vitaminol., 42, 589-593 (1996).

21) Finkelstein, J. D., and Martin, J. J., Methionine metabolism. Adapatation to methionine excess. J. Biol. Chem., 261, 1582-1587 (1986).

22) Finkelstein, J. D., Kyle, W. E., and Harris, B. J., Methionine metabolism in mammals. Regulation of homocysteine methyltransferases in rat tissues. Arch. Biochem. Biophys., 146, 84-92 (1971). 